\title{
Conference Paper \\ PLLA/Fibrin Tubular Scaffold: A New Way for Reliable Endothelial Cell Seeding
}

\author{
Salvatrice Rigogliuso, ${ }^{1}$ Francesco Carfi Pavia, ${ }^{2}$ Vincenzo La Carrubba, ${ }^{2}$ \\ Valerio Brucato, ${ }^{2}$ and Giulio Ghersi ${ }^{1}$ \\ ${ }^{1}$ STEBICEF, University of Palermo, Viale delle Scienze, Building 16, 90128 Palermo, Italy \\ ${ }^{2}$ DICAM, University of Palermo, Viale delle Scienze, Building 8, 90128 Palermo, Italy \\ Correspondence should be addressed to Francesco Carfi Pavia; francesco.carfipavia@unipa.it
}

Received 7 December 2013; Accepted 10 March 2014; Published 12 May 2014

Academic Editors: A. Lepedda and J. C. Rodriguez-Cabello

This Conference Paper is based on a presentation given by Vincenzo La Carrubba at "LIAC Meeting on Vascular Research 2013" held from 18 September 2013 to 21 September 2013 in Alghero, Italy.

\begin{abstract}
Copyright (C) 2014 Salvatrice Rigogliuso et al. This is an open access article distributed under the Creative Commons Attribution License, which permits unrestricted use, distribution, and reproduction in any medium, provided the original work is properly cited.

In the present work a simple and quick technique for cell seeding into tubular-shaped scaffolds, which allows a homogeneous cell distribution, was tested. The poly-L-lactide (PLLA) scaffolds, prepared via diffusion induced phase separation (DIPS), were filled with fibrin gel in order to obtain a hybrid scaffold for Vascular Tissue Engineering applications. The formation of immobilized fibrin networks on the inner surface of the tubular scaffolds was observed using confocal microscopy and SEM. Morphological analysis of the so-obtained scaffold revealed that the fibrin gel is uniformly distributed on the internal surface of the scaffold, leading to an organized structure. Moreover a penetration of the gel into the porous wall of the scaffold was observed. The in vitro endothelial cell cultures carried out in the scaffolds highlighted a faster cell proliferation inside the hybrid scaffold with respect to simple PLLA scaffold. Results show that the fibrin/PLLA hybrid scaffold may be favourably used for Vascular Tissue Engineering applications.
\end{abstract}

\section{Introduction}

Cardiovascular disease remains the leading cause of mortality in western nations, with an estimated prevalence of almost 80 million in the USA alone. In particular, coronary artery disease is the leading cause of death, accounting for $53 \%$ of the total mortality related to cardiovascular disease [1].

Tissue engineering approaches are being investigated as potential solutions to these problems.

Adhesion of tissue cells to biomaterials is a prerequisite of paramount importance for the successful incorporation of vascular implants or the colonization of scaffolds in tissue engineering applications [2].

As a matter of fact, cell adhesion plays a critical role in the normal function of mammalian cells by regulating proliferation, differentiation, and phenotypic behaviour. Initial efforts to design biomaterials have focused on achieving robust mechanical interactions between the biomaterial and adjacent cells (i.e., integration). However, evidence is emerging that cell/biomaterial interactions can affect cell/cell interactions and consequently impact tissue development and functions. Therefore, successful outcomes of tissue engineering efforts may require the development of materials that can promote and facilitate both cell/cell and cell/biomaterial adhesion [3]. Synthetic biomaterials in vascular applications, such as PLLA, poly-lactic-glycolic acid (PLGA), and $\varepsilon$ polycaprolattone (PCL), are easily modified, highly reproducible, and can be synthesized in bulk. However, synthetic polymers alone lack specific attachment sites for cell spreading, proliferation, and differentiation.

Fibrin, a major structural protein involved in wound healing, represents an ideal scaffold for the rapid synthesis of autologous tissue-engineered vascular grafts, as its primary scaffold constituents (fibrinogen and thrombin) can be isolated directly from a blood sample of the patient 
requiring the graft. Fibrin gel scaffolds offer immediate high cell seeding efficiency and homogenous distribution of cells. Despite these promising features, fibrin gel alone possesses inadequate mechanical properties to withstand implantation in the vasculature. For these reasons the combination of a synthetic biomaterial and fibrin could solve the problems related to the mechanical properties of the scaffolds and at the same time could assure high cell density efficiency.

The aim of this paper was to identify a seeding method that would allow a fast and homogeneous colonization of the luminal surface of tubular-shaped scaffold prepared via diffusion induced phase separation (DIPS), in order to obtain in a short time the formation of a differentiated endothelium.

\section{Materials}

PLLA Resomer L 209 STM was supplied by Boehringer Ingelheim Pharma KG. ECV304 (human endothelial cell vein) was supplied from ECACC. Medium Essential Medium 199 (MEM199) was supplied from Sigma. Penicillin/streptomycin and L-glutamine were supplied from EuroClone. Fetal calf serum (FCS) was supplied from Lonza. Tripsin-EDTA 10X, fibrinogen, and thrombin from bovine plasma were supplied from Sigma. Phosphate buffer saline with and without $\mathrm{Ca}^{2+}$ and $\mathrm{Mg}^{2+}$ was supplied from EuroClone. Cell Counting Kit-8 was supplied from Sigma.

\section{Methods}

3.1. Scaffold Preparation and Characterization. The PLLA vessel-like scaffolds were obtained by performing a DIPS process, after a dip-coating, around a nylon fibre with a diameter of $1.2 \mathrm{~mm}$ as described in a previous paper [4]. Briefly, in a first step (dip-coating), the fibre was first immersed into an 8\% PLLA/dioxane solution (dip-coating bath) at a temperature of $35^{\circ} \mathrm{C}$ and was slowly pulled out at a constant rate of $15 \mathrm{~cm} / \mathrm{min}$ from the solution. In a second stage (DIPS), the fibre was pool-immersed into a second bath (DIPS or coagulation bath), containing pure water at the same temperature, for 10 minutes. Finally, the fibre was extracted from the bath, rinsed in distilled water, and dried at $80^{\circ} \mathrm{C}$ for $48 \mathrm{~h}$.

Scaffold cross sections were fractured in liquid nitrogen and gold stained for Scanning Electron Microscopy (SEM) analysis in a Philips 505 Microscope.

An estimation of the scaffold's wall thickness was carried out by an analysis of at least five SEM micrographs for each sample, in order to have a statistically representative sample.

3.2. Cell Line. ECV304 cells were cultured in MEM199 added with $1 \%$ penicillin/streptomycin mix, $1 \%$ L-glutamine, and $10 \%$ FCS and incubated in humidified incubator $\left(37^{\circ} \mathrm{C} ; 5 \%\right.$ $\mathrm{CO}_{2}$ ).

3.3. Seeding of Endothelial Cell into Hybrid Scaffold PLLA/Fibrin. The tubular scaffolds (length $2 \mathrm{~cm}$ ) were sterilized with $70 \%$ ethanol overnight and rinsed extensively with an excess of 1X PBS. ECV 304 cells were enzymatically detached from plate by Trypsin 1X, centrifuged at $1000 \mathrm{rpm}$, and collected in Eppendorf tube. Cells were resuspended in a solution containing fibrinogen in culture medium previously held in ice. Immediately before seeding, an equal volume of a solution containing thrombin in culture medium was added. The final component concentrations of the cell suspension were as follows: $[3 \mathrm{mg} / \mathrm{mL}]$ fibrinogen, $[0.5 \mathrm{U} / \mathrm{mL}]$ thrombin, and 20,000 cells per linear $\mathrm{cm}$ of the scaffold. The as-prepared solution was then injected inside of each tubular scaffold, using an Eppendorf pipette $(200 \mu \mathrm{L}$ calibre). After 1 hour, complete medium was added to each sample. After welldefined culture times (2, 5, 8, and 16 days), the scaffolds were extracted from petri dishes and opportunely treated for further analysis.

3.4. Cell Viability and Proliferation. To asses cell viability and proliferation inside the tubular scaffolds, a Cell Counting Kit-8 (CCK-8), a useful sensitive colorimetric assay for the determination of the number of viable cell in cell proliferation and cytotoxicity assays, was used. Tubular scaffolds were incubated with CCK-8 solution $(1: 10)$ in Medium 199 for $4 \mathrm{hrs}$ in humidified incubator $\left(37^{\circ} \mathrm{C} ; 5 \% \mathrm{CO}_{2}\right)$. The absorbance was measured at $450 \mathrm{~nm}$ by a microplate reader and the values were compared with a calibration curve using data obtained from the culture plate, containing a known number of viable cells. A spontaneous absorbance around $460 \mathrm{~nm}$ occurs in culture medium without cell, incubated with CCK-8, and used as control. This background was subtracted from the absorbance of each sample value.

\section{Results and Discussion}

The morphology of the tubular scaffolds utilized is shown in Figure 1. The scaffold features a lumen of $1.2 \mathrm{~mm}$ and wall thickness around 150 micrometers. An analysis of the inner and outer surface of the scaffold has revealed an open structure with micropores ranging from 2 to 5 micrometers. An open porosity with interconnected pores was detected in the bulk of the wall.

One of the problems that have to be overcome in tissue engineering is the seeding efficiency. As a matter of fact, during the early stages of seeding, the injected cells tend to come out from the scaffold toward the culture plate; moreover, above all in static culture, the cells start to colonize the scaffold from its bottom and later they start to migrate covering the entire circumference of the vessel lumen, thus leading to a slow and irregular colonization of the luminal surface of the scaffold [5]. The fibrin gels have been extensively studied because of their nonlinear elasticity, characterized by soft compliance at small strains and impressive stiffening to resist larger deformations. Those features appear essential for its function as haemostatic plugs and as matrices for cell migration and wound healing [6].

Fibrinogen is a soluble $340 \mathrm{kDa}$ protein found in the blood and it is involved with both blood clotting and platelet aggregation. Fibrinogen is polymerized into fibrin by the removal of $\mathrm{A}$ and $\mathrm{B}$ peptides through the action of thrombin in the presence of $\mathrm{Ca}^{2+}$. The ability to control gelation times by altering thrombin concentrations [7] led us to choose this 


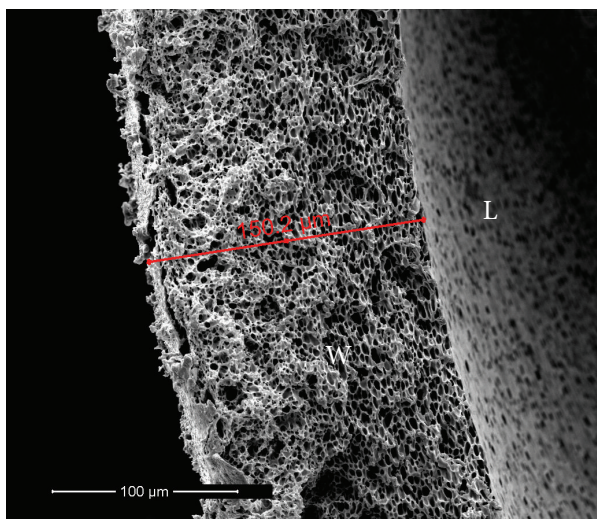

(a)

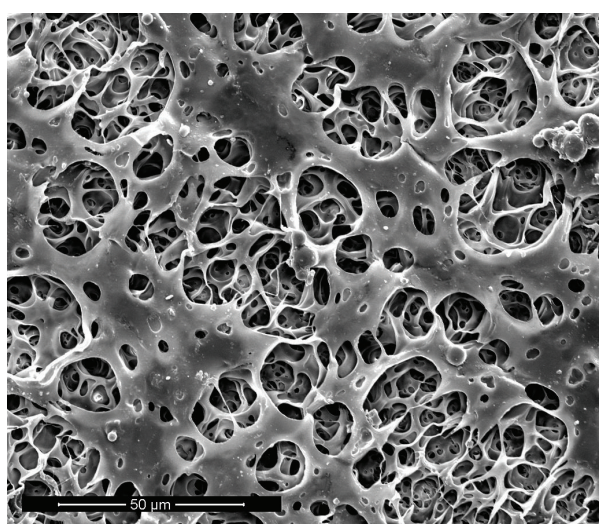

(c)

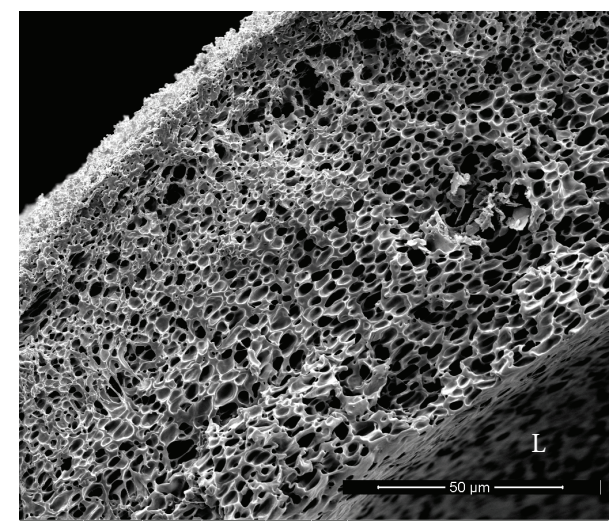

(b)

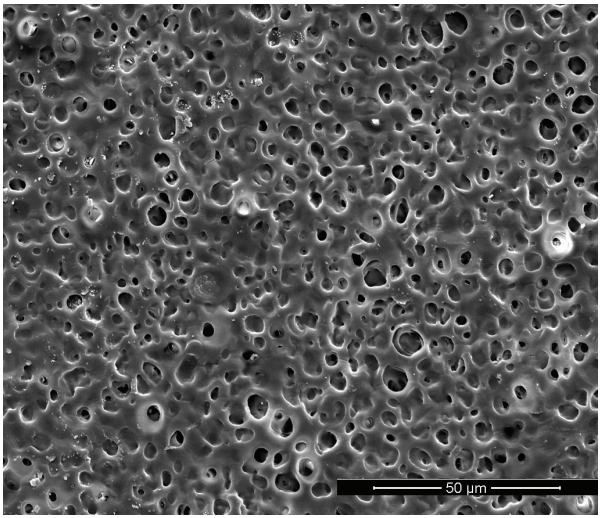

(d)

FIGURE 1: SEM analysis of vessel-like scaffold structure. (a) Cross-section of tubular scaffold; (W: external surface; L: luminal surface); (b) magnification of vessel wall; (c) outer surface; (d) inner surface.

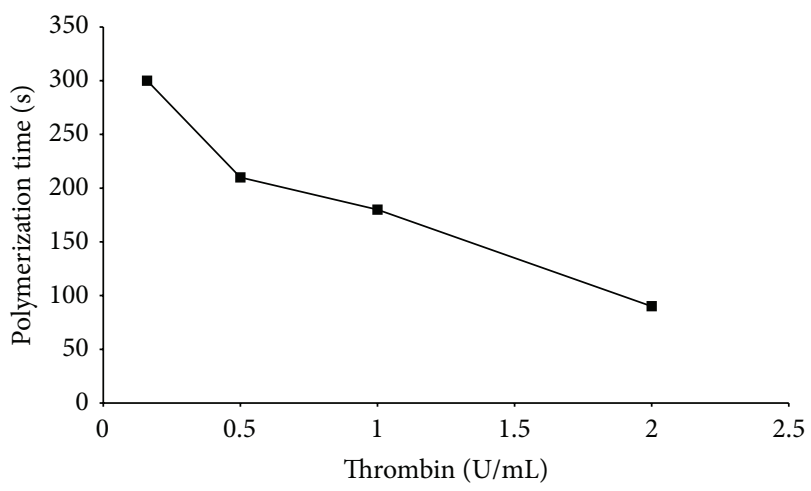

FIGURE 2: Schematization of polymerization time of fibrin gel versus the thrombin concentration (units/mL).

protein for the generation of a hybrid scaffold with increased mechanical properties and better adhesive ability.

In order to promote a homogeneous cell attachment and higher seeding efficiency in terms of effective number of cell seeded into the tubular scaffold, a new seeding protocol based on the injection of a mixture of fibrinogen, thrombin, and endothelial cells inside vessels was set up and tested.

The first step of the present research was focused on the control of the parameters that influence the time of polymerization of the fibrin gel. Figure 2 shows the time of polymerization of fibrin gel versus the thrombin concentration (units/mL).

It is easy to notice that the time of polymerization decreases when increasing the thrombin concentration. The final concentrations chosen for fibrinogen and thrombin were, respectively, $3 \mathrm{mg} / \mathrm{mL}$ and $0.5 \mathrm{U} / \mathrm{mL}$. The choice of these conditions has allowed us to obtain an injectable solution that does not polymerize for at least $210 \mathrm{sec}$ (3.5 minutes), a reasonable time for the seeding procedure inside the tubular scaffold.

The images obtained by LSCM and SEM analysis in Figure 3 showed that the fibrin gel covers the internal surface of the scaffold and also penetrates into the micropores of the wall of the vessel-shaped scaffold.

The obtained structure should improve the level of adhesiveness on the luminal wall and, as described in the literature, drive the migration of cells through the porosity of the wall, supporting cellular cultures in generating vessellike networks [8]. Once the protocol of seeding was standardized, biological assays were carried out in order to test the efficiency of the technique utilized.

\section{Proliferation Assay}

Cell proliferation on tubular scaffolds was assessed via. an enzymatic colorimetric assay, using the reagent CCK-8. 


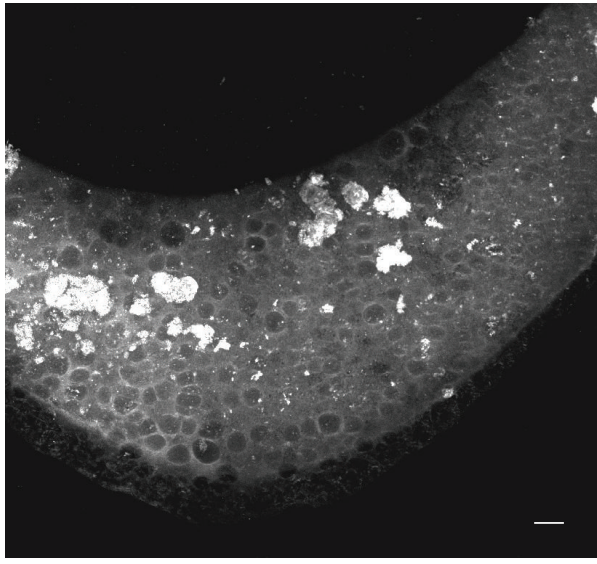

(a)

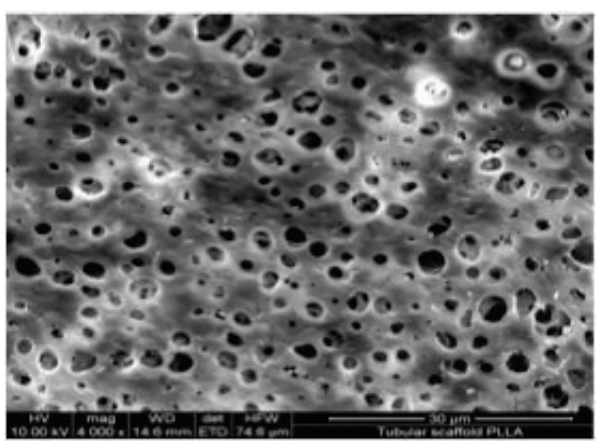

(c)

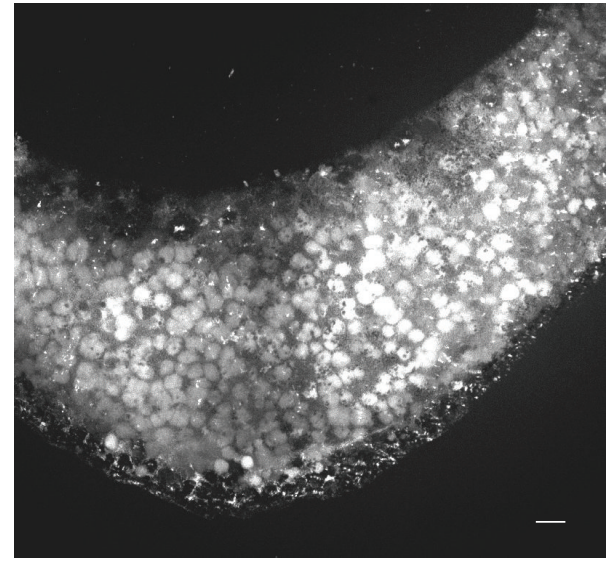

(b)

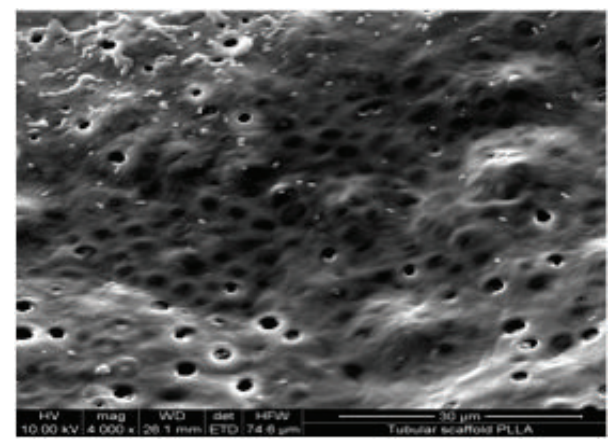

(d)

Figure 3: Analysis of fibrin matrix into the PLLA scaffold. LSCM (a-b) and SEM analysis (c-d) show the fibrin gel localization. (a-c) PLLA tubular scaffold not treated with fibrin gel. (b-d) PLLA/fibrin tubular scaffold. (a-b) Magnification: 40x. Scale bar: $15 \mu \mathrm{m}$. (c-d) Magnification: 4000x. Scale bar: $30 \mu \mathrm{m}$.

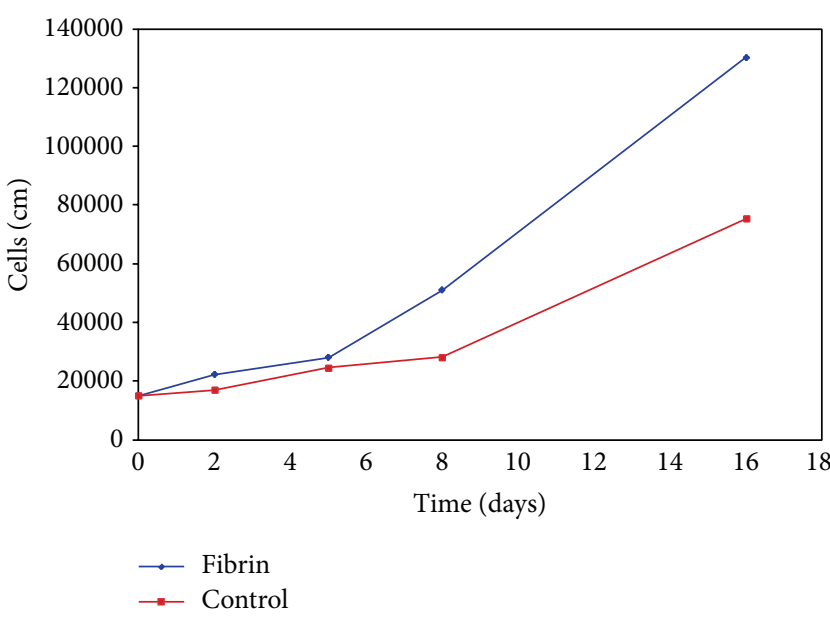

(a)

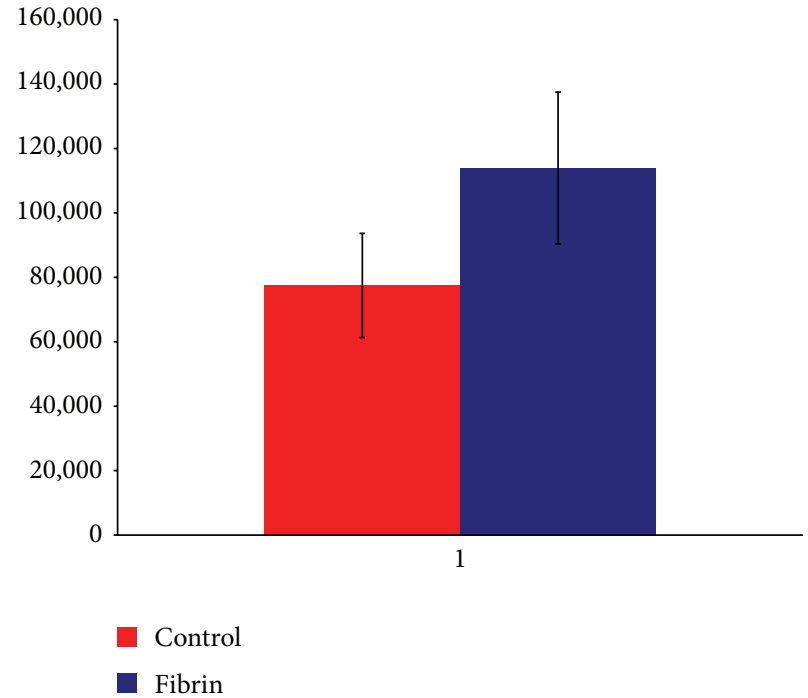

(b)

Figure 4: Proliferation assay. (a) Growth curves of ECV304 seeded into the PLLA/fibrin scaffold (grey line) and PLLA scaffold (black line). (b) Densitometric analysis of LSCM images carried out with Image-J software. The cell density of each field was quantified and reported in histogram as grey density chosen from eight arbitrary fields along the diagonal of each image. 
In Figure 4(a), the growth curves of the cells seeded into the PLLA/fibrin scaffold and PLLA scaffold are shown. No significant differences in terms of cells per scaffold were observed in the first days of culture for both systems. After 8 days, a faster proliferation was recorded for the cells grown into the PLLA/fibrin scaffold. After 16 days, the number of the cells in the PLLA/fibrin scaffold is almost twofold with respect to PLLA scaffold.

In both cases the ECV304 cells quickly take contact with the polymeric matrix; however, it is possible to hypothesize that, if harnessed in the fibrin gel, contact with the walls of the scaffold and the radial growth within the vessel lumen were facilitated. The result was confirmed from densitometric analysis of LSCM images (Figure 4(b)) that shows that the PLLA/fibrin hybrid scaffold is colonized by a greater number of cells.

\section{Conclusion and Future Purposes}

The described endothelial cell seeding method inside a fibrin gel support induces a double effect. On one hand, the possibility of seeding a very large cell number in one step with the capability to colonize the scaffold in a relative short time was given; on the other hand, the hybrid scaffold could play the role of a key stimulator of neovascularization and perfusion of implanted grafts.

In light of data obtained and from what the literature about the fibrin influence on angiogenic differentiation suggests [9], PLLA/fibrin scaffolds may actively support the vascularization process required in many tissue engineering applications.

\section{Conflict of Interests}

The authors declare that there is no conflict of interests regarding the publication of this paper.

\section{References}

[1] L. Soletti, Y. Hong, J. Guan et al., "A bilayered elastomeric scaffold for tissue engineering of small diameter vascular grafts," Acta Biomaterialia, vol. 6, no. 1, pp. 110-122, 2010.

[2] N. Faucheux, R. Schweiss, K. Lützow, C. Werner, and T. Groth, "Self-assembled monolayers with different terminating groups as model substrates for cell adhesion studies," Biomaterials, vol. 25, no. 14, pp. 2721-2730, 2004.

[3] A. S. Goldstein, "Cell Adhesion," in Tissue Engineering and Artificial Organs, J. Bronzino, Ed., Chapter 34, pp. 1-18, 2006.

[4] F. Carfi' Pavia, V. La Carrubba, G. Ghersi, and V. Brucato, "Polyleft-lactic acid tubular scaffolds via diffusion induced phase separation: control of morphology," Polymer Engineering and Science, vol. 53, pp. 431-442, 2013.

[5] K. Shimizu, A. Ito, M. Arinobe et al., "Effective cell-seeding technique using magnetite nanoparticles and magnetic force onto decellularized blood vessels for vascular tissue engineering," Journal of Bioscience and Bioengineering, vol. 103, no. 5, pp. 472478, 2007.

[6] P. A. Janmey, J. P. Winer, and J. W. Weisel, "Fibrin gels and their clinical and bioengineering applications," Journal of the Royal Society Interface, vol. 6, no. 30, pp. 1-10, 2009.
[7] N. Laurens, P. Koolwijk, and M. P. de Maat, "Fibrin structure and wound healing," Journal of Thrombosis and Haemostasis, vol. 4, no. 5, pp. 932-939, 2006.

[8] A. Lesman, J. Koffler, R. Atlas, Y. J. Blinder, Z. Kam, and S. Levenberg, "Engineering vessel-like networks within multicellular fibrin-based constructs," Biomaterials, vol. 32, no. 31, pp. 78567869, 2011.

[9] V. W. M. Van Hinsbergh, A. Collen, and P. Koolwijk, "Role of fibrin matrix in angiogenesis," Annals of the New York Academy of Sciences, vol. 936, pp. 426-437, 2001. 


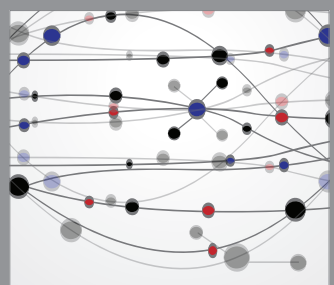

The Scientific World Journal
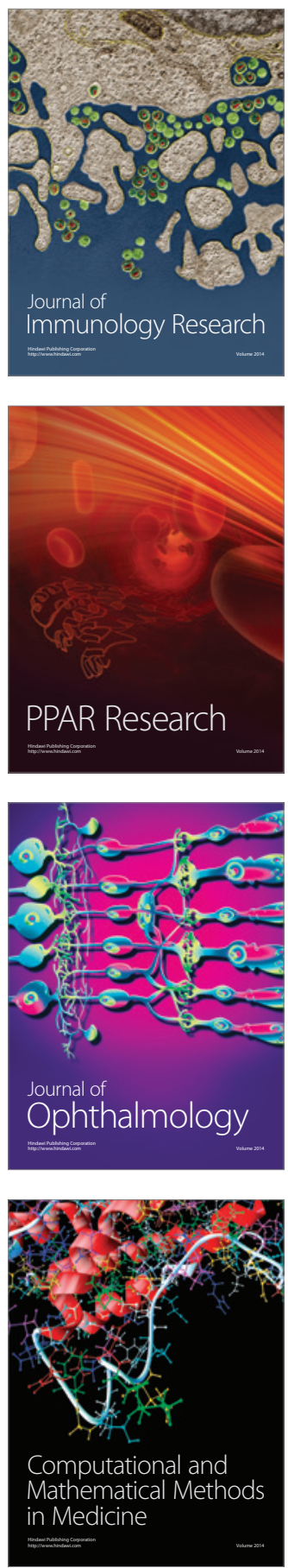

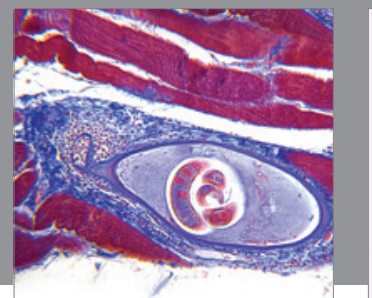

Gastroenterology

Research and Practice
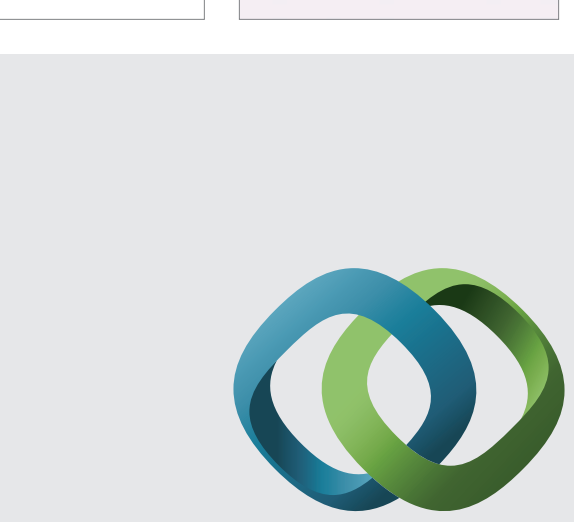

\section{Hindawi}

Submit your manuscripts at

http://www.hindawi.com
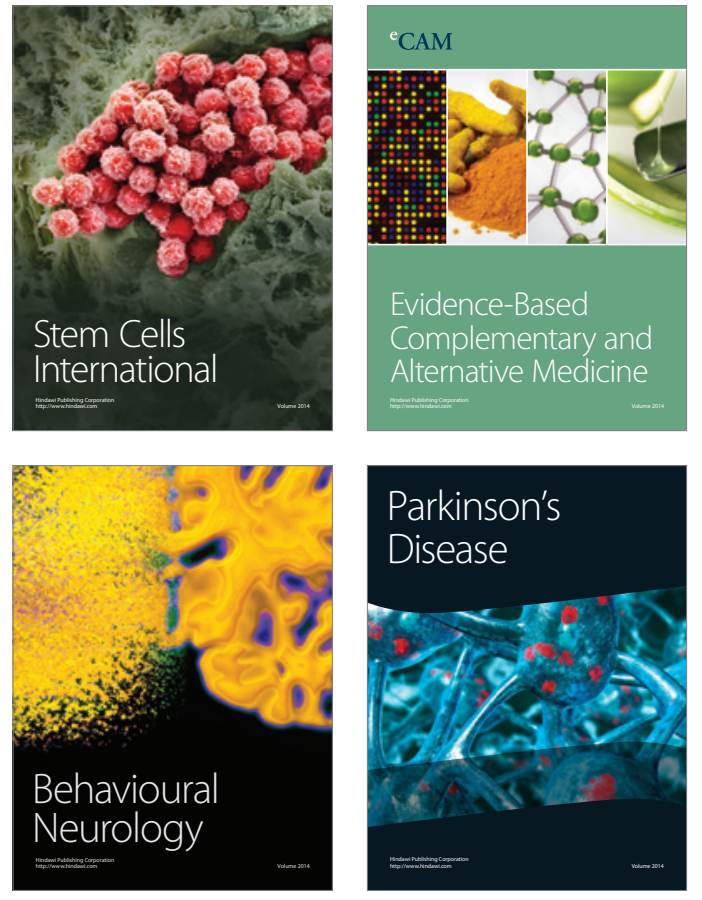
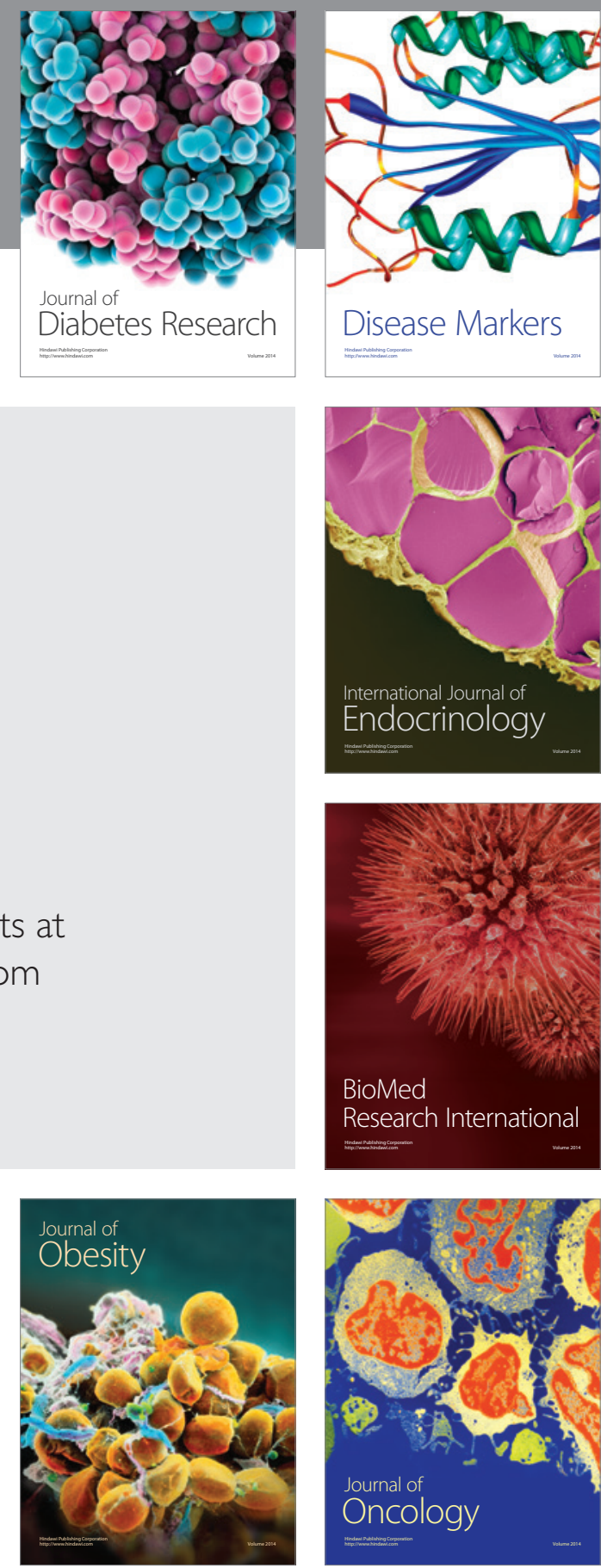

Disease Markers
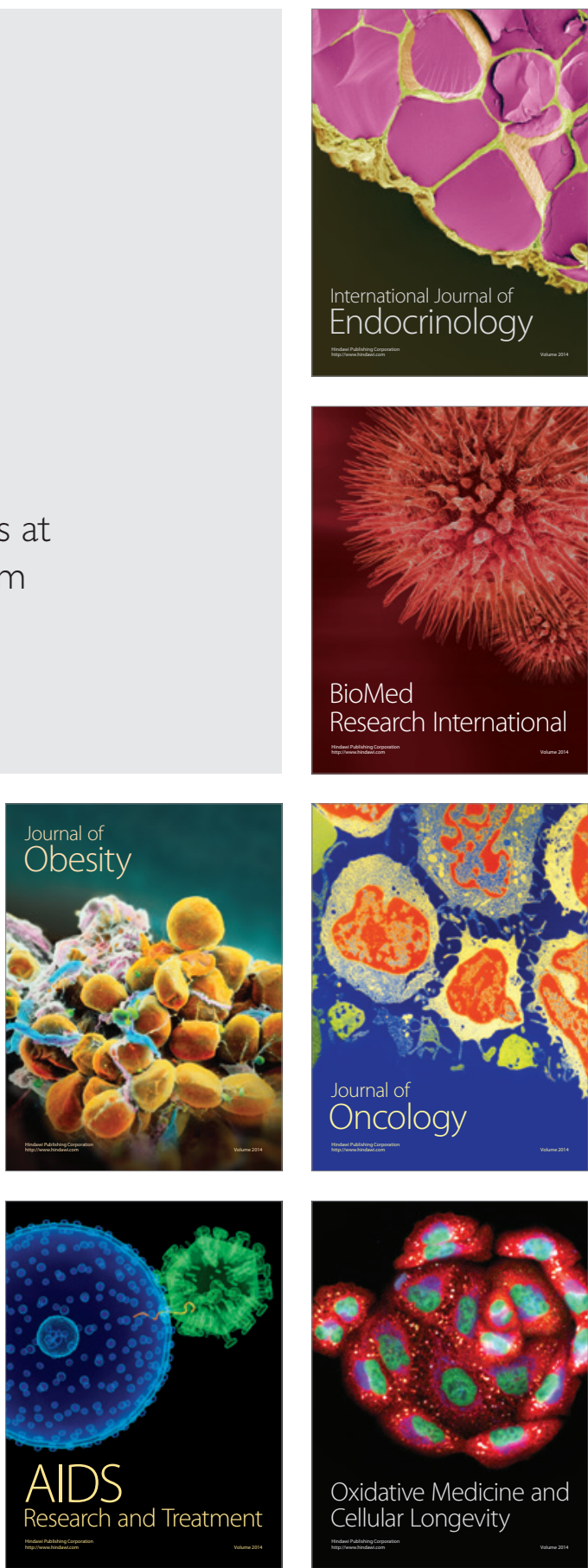